University of Nebraska - Lincoln

DigitalCommons@University of Nebraska - Lincoln

1998

\title{
Comparisons of Two Polymorphic Species of Ostertagia and Phylogenetic Relationships within the Ostertagiinae (Nematoda: Trichostrongyloidea) Inferred from Ribosomal DNA Repeat and Mitochondrial DNA Sequences
}

Dante S. Zarlenga

Agricultural Research Service, Immunology and Disease Resistance Laboratory, United States Department of Agriculture

Eric P. Hoberg Agricultural Research Service, Immunology and Disease Resistance Laboratory, United States Department of Agriculture, ehoberg@ggpl.arsusda.gov

Frank Stringfellow

Agricultural Research Service, Immunology and Disease Resistance Laboratory, United States Department of Agriculture

J. Ralph Lichtenfels

Animal Parasitic Disease Lab, ARS, United States Department of Agriculture, 2jrcgl@gmail.com

Follow this and additional works at: https://digitalcommons.unl.edu/parasitologyfacpubs

Part of the Parasitology Commons

Zarlenga, Dante S.; Hoberg, Eric P.; Stringfellow, Frank; and Lichtenfels, J. Ralph, "Comparisons of Two Polymorphic Species of Ostertagia and Phylogenetic Relationships within the Ostertagiinae (Nematoda: Trichostrongyloidea) Inferred from Ribosomal DNA Repeat and Mitochondrial DNA Sequences" (1998). Faculty Publications from the Harold W. Manter Laboratory of Parasitology. 637.

https://digitalcommons.unl.edu/parasitologyfacpubs/637

This Article is brought to you for free and open access by the Parasitology, Harold W. Manter Laboratory of at DigitalCommons@University of Nebraska - Lincoln. It has been accepted for inclusion in Faculty Publications from the Harold W. Manter Laboratory of Parasitology by an authorized administrator of DigitalCommons@University of Nebraska - Lincoln. 


\title{
COMPARISONS OF TWO POLYMORPHIC SPECIES OF OSTERTAGIA AND PHYLOGENETIC RELATIONSHIPS WITHIN THE OSTERTAGIINAE (NEMATODA: TRICHOSTRONGYLOIDEA) INFERRED FROM RIBOSOMAL DNA REPEAT AND MITOCHONDRIAL DNA SEQUENCES
}

\author{
Dante S. Zarlenga, Eric P. Hoberg*, Frank Stringfellow, and J. Ralph Lichtenfels* \\ U.S. Department of Agriculture, ARS, Immunology and Disease Resistance Laboratory, Beltsville, Maryland 20705
}

\begin{abstract}
The first internal transcribed spacer DNA (ITS-1) (rDNA) and the mitochondrial (mt) DNA-derived cytochrome oxidase I gene (COX-1) were enzymatically amplified, cloned and sequenced from 6 nominal species of Ostertagiinae as well as Haemonchus contortus and Haemonchus placei. The portion of the COX-1 gene analyzed was 393 base pairs (bp) in length and contained 33 within species polymorphic base changes at 28 synonymous sites. The ITS- 1 rDNA consensus sequences ranged from $392 \mathrm{bp}$ (Ostertagia ostertagi/Ostertagia lyrata, Teladorsagia circumcincta) to $404 \mathrm{bp}(\boldsymbol{H}$. contortus, $\mathrm{H}$. placei). These data were used both in a distance analysis to assess the concept of polymorphic species within the genus Ostertagia and in parsimony analysis to assess phylogenetic relationships within a limited group of Ostertagiinae. Pairwise similarity scores of both ITS-1 and COX-1 data showed the highest number of conserved sites between the proposed dimorphic species of Ostertagia. The level of similarity was lower in the COX-1 data due to the high number of synonymous base changes. Analysis by maximum parsimony of the same data did not refute $O$. ostertagi/O. lyrata and Ostertagia mossi/Ostertagia dikmansi as dimorphic species and supported monophyly of these ostertagiines relative to representatives of the haemonchine outgroup. In the single most parsimonious tree from ITS-1 rDNA data, a subclade of Ostertagia spp. included forms possessing parallel synlophes and long esophageal valves that typically occur in cervid hosts.
\end{abstract}

A major advancement in the systematics of the Ostertagiinae was the recognition of polymorphism in males (Daskalov, 1974; Drózdz, 1974; Lancaster and Hong, 1981). The occurrence of polymorphism among genera and species within the Ostertagiinae was reviewed recently by Drózdz (1995). A partial list of those he had studied from the Palearctic included 19 polymorphic species in 5 genera. Studies on parasite hybridization (Suarez and Cabaret, 1992), synlophe structure (Lichtenfels and Hoberg, 1993), environmental effects (Suarez et al., 1995), allozymes (Gasnier et al., 1993), and random amplified polymorphic DNA (Humbert and Cabaret, 1995) have not refuted the hypothesis that members of the "species pairs" are dimorphic males of a single species. One study utilizing DNA sequence data to study polymorphic species within the genus Teladorsagia Andreeva and Satubaldin, 1954 has been undertaken (Stevenson et al., 1996); however, the application of both nuclear and mitochondrial-derived sequence data to study dimorphic species within the Ostertagiinae are lacking.

DNA sequence data has long been used to assess relationships among organisms. Specifically, various regions of the ribosomal DNA (rDNA) and mitochondrial DNA (mtDNA) have received the most attention when studying more divergent taxa (rDNA) or more recently derived species (mtDNA). Studies by Zarlenga, Stringfellow, and Lichtenfels (1994) and Zarlenga, Stringfellow, Nobary, and Lichtenfels (1994) suggested that within genera of trichostrongyles, the small subunit rDNA molecule ( $s s r D N A$ ) is unlikely to provide adequate information to assess phylogenetic relationships because of the high level of sequence conservation among this group of parasites. However, the internal transcribed spacer (ITS) region has received substantial attention as a sequence that bridges the gap of utilizing nuclear sequences to assess more recently evolved species because of the higher degree of sequence variability. Studies in-

Received 24 June 1997; revised 9 February 1998; accepted 11 April 1998.

* U.S. Department of Agriculture, ARS, Biosystematics and National Parasite Collection Unit, Beltsville, Maryland 20705. volving sequence analysis of external and internal transcribed spacers of the rDNA repeat of other nematodes (Zarlenga, Stringfellow, and Lichtenfels, 1994; Zarlenga, Stringfellow, Nobary, and Lichtenfels, 1994; Hoste et al., 1995) have shown them to be of value for species level systematics of nematodes, including species of Haemonchus Cobb, 1898 and Trichostrongylus Looss, 1905, and for assessing divergence among polymorphs of Teladorsagia circumcincta (Stadelmann, 1894) (see Stevenson et al., 1996).

This report presents sequence data for the first internal transcribed spacer (ITS-1) of the rDNA repeat and partial data from the mitochondrial-derived, cytochrome oxidase 1 (COX-1) gene of 2 putative polymorphic species, Ostertagia ostertagi (Stiles, 1892)/Ostertagia lyrata Sjoberg, 1926 and Ostertagia mossi Dikmans, 1931/Ostertagia dikmansi Becklund and Walker, 1968. For additional within group comparison, similar data are provided for Ostertagia leptospicularis Assadov, 1953, and T. circumcincta. Haemonchus contortus (Rudolphi, 1802), and Haemonchus placei (Place, 1893), representing the putative sister-group, Haemonchinae, are included as the basis of outgroup comparison (Hoberg and Lichtenfels, 1994). Utilizing these data we provide first, a test of the polymorphism hypothesis based on pairwise similarity scores from molecular sequences of 2 independent DNA regions and second, examine putative evolutionary relationships of the taxa based upon cladistic analysis of the sequence data.

\section{MATERIALS AND METHODS}

\section{Specimens}

Adult nematodes were obtained from hosts experimentally infected at Beltsville or collected elsewhere from naturally infected hosts, quick frozen and shipped to Beltsville for identification (Table I). Specimens were identified to species using characteristics of spicules, copulatory bursa, genital cone, esophagus and synlophe (males) or characteristics of the ovejectors, tail, esophagus and synlophe (females) (Durette-Desset, 1982; Lichtenfels and Hoberg, 1993; Lichtenfels et al., 1994). 
TABLE I. Source of nematodes studied.

\begin{tabular}{lll}
\hline \multicolumn{1}{c}{ Nematode species } & \multicolumn{1}{c}{ Host } & \multicolumn{1}{c}{ Locality and source } \\
\hline Ostertagia ostertagi & Bos taurus & Beltsville, Maryland (L. C. Gasbarre)* \\
Ostertagia lyrata & B. taurus & Weybridge, England (M. B. Lancaster)* \\
Ostertagia mossi & Odocoileus virginianus & Mississippi (C. E. Couvillion) $\dagger$ \\
Ostertagia dikmansi & O. virginianus & Mississippi (C. E. Couvillion) $\dagger$ \\
Ostertagia leptospicularis & B. taurus & Weybridge, England (M. B. Lancaster)* \\
Teladorsagia circumcincta & Ovis aries & Beltsville, Maryland (F. Stringfellow)* \\
Haemonchus contortus & B. taurus & Beltsville, Maryland (L. C. Gasbarre)* \\
Haemonchus placei & B. taurus & Austrialia (W. L. Shoop)* \\
\hline
\end{tabular}

* Larvae from various sources used to infect experimental host at Beltsville, Maryland.

$\dagger$ Adults collected and shipped frozen to Beltsville, Maryland.

\section{Polymerase chain reaction (PCR) amplification and cloning}

Genomic DNA was isolated by proteinase $\mathrm{K}$-sodium dodecyl sulfate (SDS) digestion from a pooled sample of adult parasites as previously described (Dame et al., 1987) without prior homogenization. The COX1 gene was enzymatically amplified using evolutionarily conserved $\mathrm{Fas}$ ciola hepatica-derived primers 239 (5'AAAGGAATTCTTTTTTGGGCATCCTGAGGTTTAT) and 240 (5'ATTGGATCCTAAAGAAAGAACATAATGAAAATG) (Garey and Wolstenholme, 1989) to which EcoRI and BamHI restriction sites (underlined) had been added, respectively. The data presented represent partial COX-1 sequence information. The sequence encoding ITS-1 was amplified from genomic DNA using primers 241 (5'AAAGGAATTCAAGTCGTAACAAGG-

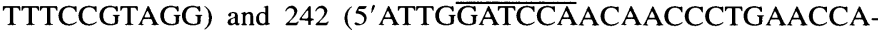
GACGTAC) that also contain EcoRI and BamHI restriction sites (underlined) for cloning. The primers are complementary to the 3' end of the ssrRNA and the 3 ' end of the 5.8S rRNA, respectively. Amplification was performed in a $100-\mu l$ reaction mixture containing $50 \mathrm{mM}$ $\mathrm{KCl}, 10 \mathrm{mM}$ Tris- $\mathrm{HCl}, \mathrm{pH} 8.3,1.5 \mathrm{mM} \mathrm{MgCl}_{2}, 10 \mathrm{nmol}$ each deoxynucleotide triphosphate, $0.2 \mu \mathrm{M}$ of each primer, and $2.5 \mathrm{U}$ of Taq DNA polymerase for 35 cycles as follows: $1 \mathrm{~min}$ at $94 \mathrm{C}, 1 \mathrm{~min}$ at $55 \mathrm{C}$, and $2 \mathrm{~min}$ at $72 \mathrm{C}$, followed by a final $7 \mathrm{~min}$ at $72 \mathrm{C}$ extension. PCR products were restriction enzyme-digested with EcoRI and BamHI, agarose gel purified, and ligated overnight to similarly digested pUC 18 plasmid DNA in the presence of T4 DNA ligase. The next day, recombinant plasmids were used to transform electrocompetent DH5 $\alpha$ bacterial cells. For each sequence, 2 clones were picked, verified for correctness, and independently sequenced using universal forward and reverse pUC primers.

\section{Sequence analysis}

Sequence analysis was performed using Sequenase ${ }^{\mathrm{TM}}$ (Amersham, Arlington Heights, IL) according to the manufacturer's recommendations. Homologous sequences from each species of parasite were aligned both visually and through the Intelligenetics PCGENE version of the Clustal alignment program by Higgins and Sharp (1988). Transitions were weighted twice as likely as transversions and the gap pen- alty was 5 . Computation of pairwise similarity scores were based upon the method of Wilbur and Lipman (1983) and tabulated for the ITS-1 data (Table II) and the COX-1 data (Table III). Due to the high level of synonymous base changes and polymorphic sites observed in the COX-1 sequences, the DNA data were analyzed without modification (Table III), by eliminating the third base of the amino acid codon (Table III) and as predicted amino acid sequences (not shown).

Relationships among all parasite groups presented herein were analyzed by maximum parsimony with PAUP 3.1 (Swofford, 1993). Polarity was determined with reference to the haemonchine outgroup $(H$. contortus and $\mathrm{H}$. placei), the putative sister-group for the Ostertagiinae, based on phylogenetic analysis and comparative morphology (Hoberg and Lichtenfels, 1994). Characters were equally weighted and an exhaustive search was conducted. Unambiguous gaps were treated as a fifth character. Bootstrap resampling with 1,000 replicates was performed to examine relative support for clades recovered in the respective analyses. Results are shown as phylogenetic trees with accompanying descriptive statistics including the consistency index (CI), homoplasy index (HI), retention index (RI), and rescaled consistency in$\operatorname{dex}(\mathrm{RC})$ as defined by Swofford (1993). Results from bootstrap analyses are shown as a $50 \%$ majority-rule consensus tree.

\section{RESULTS}

\section{Pairwise similarity scores}

Enzymatic amplification of the ITS-1 rDNA generated 2 distinct size fragments within this group of parasites. The ITS-1 rDNA for $O$. ostertagia and $O$. lyrata was approximately 1,000 base pairs (bp), whereas the homologous sequence in all other trichostrongyles was only $600 \mathrm{bp}$ (approximate). This size difference was the result of a 408-bp insertion within the $O . o s t e r t a g i$ and $O$. lyrata genomes (data not shown).

The ITS-1 rDNA data (Fig. 1) consisted of a contiguous stretch of 392-404 bp (with the exception of O.ostertagi/

TABLE II. Pairwise similarity scores for ITS-1 DNA sequences of 6 nominal species of Ostertagiinae and Haemonchus spp.

\begin{tabular}{|c|c|c|c|c|c|c|c|c|}
\hline Nematode species & 1 & 2 & 3 & 4 & 5 & 6 & 7 & 8 \\
\hline 1. O. ostertagi* & $(392) \dagger$ & - & - & - & - & - & - & - \\
\hline 2. O. lyrata* & 391 & $(392)$ & - & - & - & - & - & - \\
\hline 3. O. mossi & 315 & 315 & $(400)$ & - & - & - & - & - \\
\hline 4. O. dikmansi & 315 & 315 & 400 & $(400)$ & - & - & - & - \\
\hline 5. O. leptospicularis & 319 & 319 & 366 & 366 & $(401)$ & - & - & - \\
\hline 6. T. circumcincta & 323 & 322 & 314 & 314 & 323 & (392) & - & - \\
\hline 7. H. contortus & 269 & 269 & 275 & 275 & 276 & 296 & (404) & - \\
\hline 8. H. placei & 269 & 269 & 272 & 272 & 276 & 295 & 400 & (404) \\
\hline
\end{tabular}

* Table excludes sequence inserts in $O$. ostertagi and $O$. lyrata.

$\dagger$ Numbers in parentheses are total number of bases. Within the ITS-1 region, sequence length was not conserved. 
TABLE III. Pairwise similarity scores for COX-1 DNA sequences among 6 nominal species of Ostertagiinae and Haemonchus spp.

\begin{tabular}{|c|c|c|c|c|c|c|c|c|}
\hline Nematode species & 1 & 2 & 3 & 4 & 5 & 6 & 7 & 8 \\
\hline 1. O. ostertagi & - & $376^{*}$ & 337 & 336 & 340 & 332 & 335 & 327 \\
\hline 2. O. lyrata & $261 \dagger$ & - & 339 & 339 & 339 & 335 & 337 & 329 \\
\hline 4. O. dikmansi & 259 & 258 & 262 & - & 334 & 329 & 336 & 331 \\
\hline 5. O. leptospicularis & 261 & 260 & 260 & 260 & - & 339 & 338 & 335 \\
\hline 6. T. circumcincta & 260 & 259 & 256 & 256 & 259 & - & 337 & 337 \\
\hline
\end{tabular}

* Numbers above diagnonal include all COX-1 sequence data; consensus length $=393 \mathrm{bp}$.

$\dagger$ Numbers below diagnonal include only bases 1 and 2 of amino acid codons; consensus length $=262$ bp.

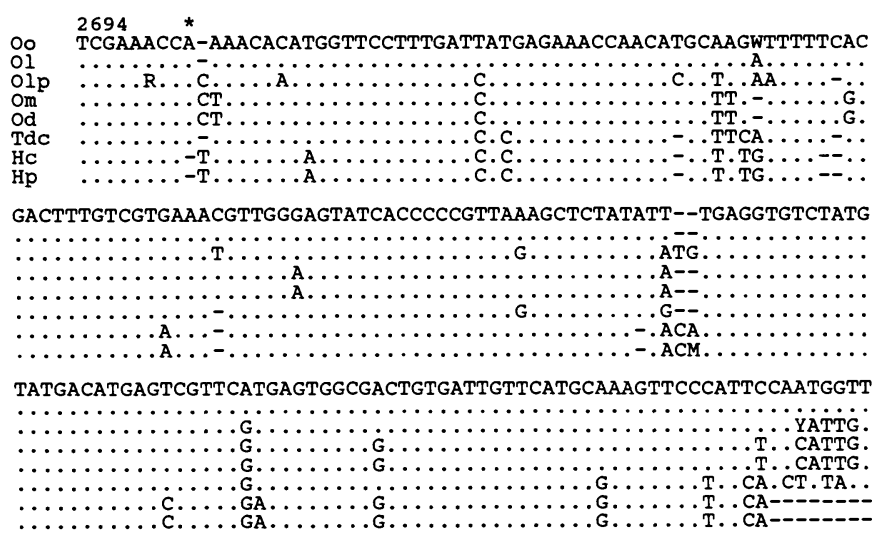

GGTTATGGTTGAGCTTGAGACTTAATGAGTATTGCTATAATACCGCCTCATTGCATTTATAATGG

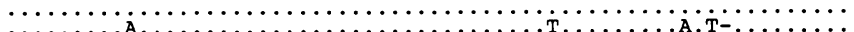

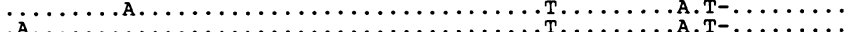

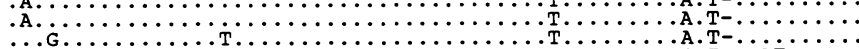

-T.G.

TGGYTATGTACATAC------------GTGTA-GTATGTACGGTACCTGGTTGT--CAGGAA

$\because$ Т. $\ldots \ldots \ldots$ с.

$\cdots$ T. $\cdots, \ldots$ C.T-T.

:T.

ACCTTAATGATCTCGCCTAGACGCCATTATAAAACA-CAACTTTTTATGTTTAAAGTTTGCAGAA

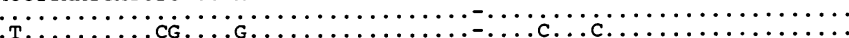

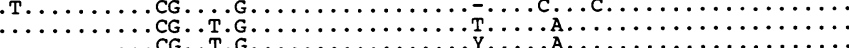

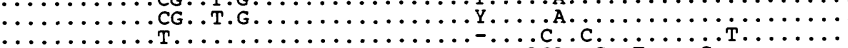

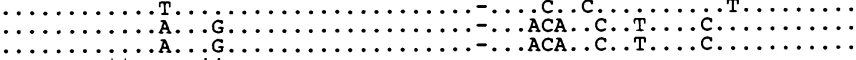

AT--GTGTACACAGAAA--TGTGTCACAATT---GAC 3'

-

-

C.

С- $\ldots$ T. $\ldots$ TT- TT $\ldots \ldots \ldots \ldots$ A.ATC.

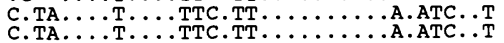

FIGURE 1. Comparison of the ITS-1 rDNA sequences from 5 species of Ostertagia, 1 species of Teladorsagia and 2 species of Haemonchus. The site of sequence discontinuity within $O$. ostertagi and $O$. lyrata due to the presence of a 408 -bp insert is indicated by $\downarrow \downarrow$. Gaps denoted by * were not used as fifth characters in arriving at the tree shown in Figure 3. Base pair numbering is in accordance with that for Caenorhabditis elegans. $\mathrm{M}=\mathrm{A}, \mathrm{C} ; \mathrm{R}=\mathrm{A}, \mathrm{G} ; \mathrm{W}=\mathrm{A}, \mathrm{T} ; \mathrm{Y}=\mathrm{C}, \mathrm{T}$. Oo, O. ostertagi; Ol, O. lyrata; Om, O. mossi; Od, O. dikmansi; Olp, O. leptospicularis; Tdc, T. circumcincta; Hc, H. contortus; $\mathrm{Hp}, H$. placei. Sequences shown in Figure 1 have been assigned Genbank accession numbers AF044927-AF044934.
O.lyrata). Sequence alignment for the dimorphic species showed a consensus of 391 of 392 base pairs between $O$. ostertagi and $O$. lyrata with 2 additional polymorphic sites within the ITS-1 region. No differences were observed between $O$. mossi and $O$. dikmansi; however, 1 polymorphic site was identified. All polymorphic sites contained one base consistent with the consensus sequence. Pairwise similarity scores indicated that sequences of morphs within each dimorphic species were most similar and substantially distinct from all other parasites analyzed (Table II).

When the COX-1 gene was similarly amplified using $F$. hepatica-derived COX-1 primers, a single fragment was produced for all taxa examined that was approximately $450 \mathrm{bp}$ in size. The aligned region of the COX-1 gene was $393 \mathrm{bp}$ in length and contained 33 polymorphic bases within 28 polymorphic sites among all 6 taxa (Fig. 2). All polymorphic sites occurred within the third base positions of amino acid codons. Pairwise similarity scores (Table III) were consistent with that derived from the ITS-1 data; however, due to the sequence polymorphism in this gene, the level of similarity between polymorphic species was substantially lower than that derived from the ITS1 data. Analysis of all COX-1 sequence data indicated a consensus of 376 of $393 \mathrm{bp}$ for O. ostertagi/O. lyrata and 390 of $393 \mathrm{bp}$ for $O$. mossi/O. dikmansi. Results from analyzing the first 2 bases of the amino acid codons revealed a consensus of 261 of 262 bp between $O$. ostertagi and $O$. lyrata and no differences between $O$. mossi and $O$. dikmansi.

\section{Maximum parsimony}

Parsimony analysis of the ITS-1 rDNA data produced 1 tree of 140 steps $(\mathrm{CI}=0.92, \mathrm{HI}=0.079, \mathrm{RI}=0.92$, and $\mathrm{RC}=$ 0.85 ) consistent with monophyly for the Ostertagiinae. Within Ostertagiinae, $T$. circumcincta is basal and $O$. ostertagi/O. lyrata is presented as the putative sister species of $O$. leptospicularis $+O$. mossi/O. dikmansi. The bootstrap consensus tree (Fig. 3) was well supported and identical to the single most parsimonious tree.

Because of the high level of polymorphic sites and synonymous base changes within this gene, parsimony analysis of the COX-1 DNA sequences did not fully resolve relationships among the 6 taxa. Parsimony analyses using all base pair sites, the first 2 bases of amino acid codons only, or predicted amino acids (data not shown) were all unresolved. Congruence among the analyses was limited to support of monophyly for the Ostertagiinae where $O$. mossi and $O$. dikmansi were consistently 


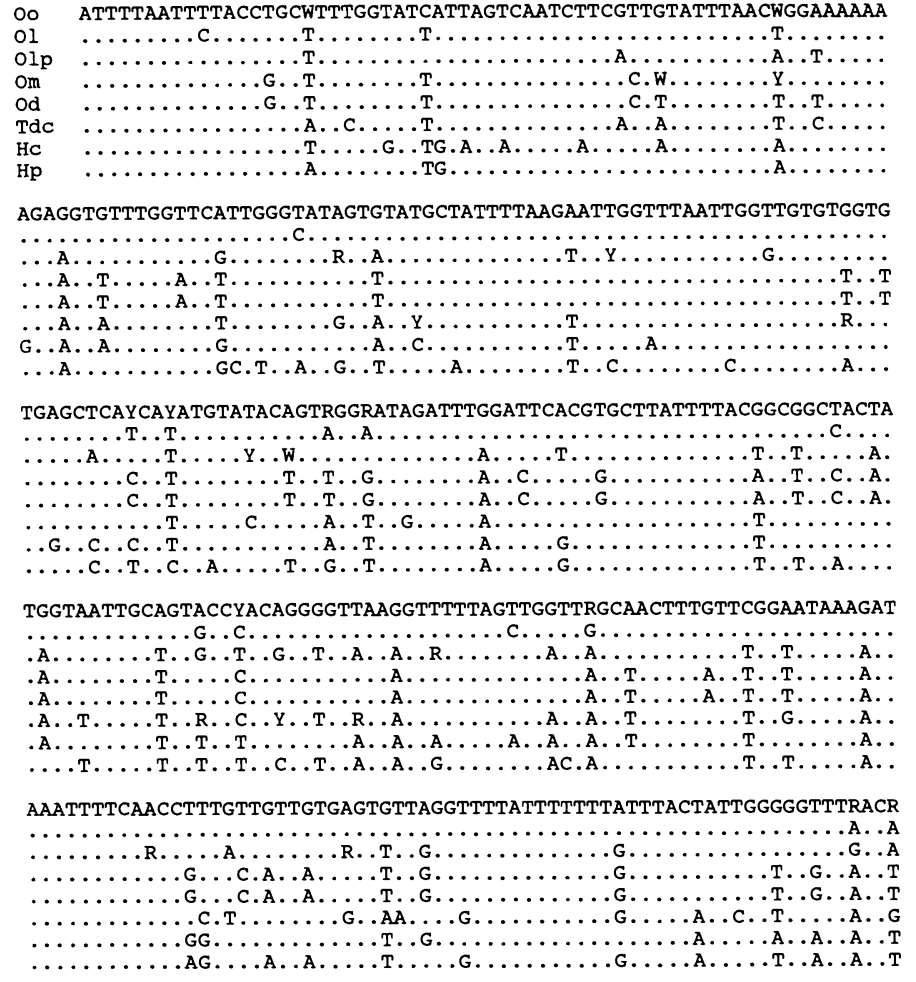

GGTGTAATTTTGTCCAATTCTAGTTTGGATATTATTTTGCATGATACTTATTATGTGGTTAGY

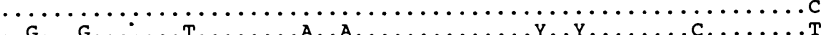
TG. $\ldots$ TG $\ldots$ A.T T. $\ldots \ldots$ T... $\ldots \ldots \ldots \ldots$ A.....A.A. . ...................

FIGURE 2. A comparison of the mtDNA-derived cytochrome oxidase I gene sequences from 5 species of Ostertagia, 1 species of Teladorsagia, and 2 species of Haemonchus. $\mathrm{R}=\mathrm{A}, \mathrm{G} ; \mathrm{W}=\mathrm{A}, \mathrm{T} ; \mathrm{Y}=\mathrm{C}, \mathrm{T}$ Oo, O. ostertagi; Ol, O. lyrata; Om, O. mossi; Od, O. dikmansi; Olp O. leptospicularis; Tdc, T. circumcincta; Hc, H. contortus; Hp, H. pla cei. Sequences shown in Figure 1 have been assigned Genbank accession numbers AF044935-AF044942.

grouped together; however, $O$. ostertagi and $O$. lyrata were periodically joined in a polytomy with other ostertagiines.

Morphological characters representative of the taxa as well as the ITS-1 sequence repeat of $O$. ostertagi/O. lyrata were mapped onto the single most parsimonious tree generated from ITS-1 rDNA data (Fig. 4). Phylogenetic groupings inferred from recent morphological analyses are supported by the ITS1 rDNA-based consensus tree.

\section{DISCUSSION}

We have analyzed sequence data from the ITS- 1 and the mtDNA-derived COX-1 gene in order to first test the hypothesis of polymorphism for $O$. ostertagi/O. lyrata and $O$. mossi/O. dikmansi and second to infer phylogenetic relationships of the Ostertagiinae studied herein. Although a subfamily analysis requires the study of more taxa than included in this study, the examination of nuclear DNA sequences for 6 nominal species of the Ostertagiinae including species from cervids and bovids has, nonetheless, provided a preliminary opportunity to assess putative phylogenetic relationships among these species and compare newly generated genetic data.

\section{Pairwise similarity scores}

Mitochondrial DNA sequence data, though believed to be more informative in generating gene trees congruent with species trees for recent speciation events (Moore 1995), produced essentially unresolved trees in this case. This occurred regardless of the sequence basis for the analysis. Presumably, this resulted from the high numbers of synonymous base changes observed within and between species. This is supported by work performed by Blouin et al. $(1992,1995)$ and by Tarrant et al. (1992) who demonstrated high sequence variability between mtDNA from individual $O$. ostertagi as well as other trichostrongylids both within and between populations. Pairwise sequence divergence between mtDNA for $H$. contortus and $H$. placei, for example, was $14.4 \%$, whereas the predicted amino acid data demonstrated a substantially smaller sequence divergence of $3.1 \%$. A similar pattern was observed throughout the matrix. Given that only 7 ambiguous sites were identified within all the ITS-1 rDNA sequences analyzed, and all the polymorphic sites in the mtDNA sequences were observed within the third base of the amino acid codons, we concluded that the divergence seen within the mtDNA data was not an artifact of PCR amplification.

The identical sequences for $O$. mossi/O. dikmansi and the nearly identical sequences for $O$. ostertagi/O. lyrata in the ITS1 rDNA repeat strongly support the concept of dimorphic species. The minor differences between $O$. ostertagi and $O$. lyrata, compared to those seen between other ostertagine species in this study, may be attributed to the different geographical and experimental sources of these specimens. Those of $O$. lyrata were an experimental strain from Europe that had been selected over several generations to increase the percentage of the minor morphotype males in the population. These data in conjunction with population studies performed by Blouin et al. $(1992,1995)$ and isolate differences investigated by Stevenson et al. (1996) suggest that the similarity scores are representative of interspecific variation and not substantially influenced by diversities among worm populations. These data further support the work of Stevenson et al. (1996) showing strong similarities among morphotypes of polymorphic species; however, care must be taken when using only sequence data to imply species status.

\section{Phylogenetic relationships}

Monophyly for this group of Ostertagiinae was supported by the analysis of both ITS- 1 and COX-1 sequence data sets. In the fully resolved ITS-1 tree, Teladorsagia is the sister-group for Ostertagia spp. and the concept of dimorphic species that was supported by pairwise similarity scores for $O$. ostertagi/O. lyrata and $O$. mossi/O. dikmansi is not refuted.

Results of the current study, though lacking the broader context of ostertagiine diversity (e.g., Durette-Desset, 1982, 1989; Gibbons and Khalil, 1982; Jansen, 1989; Drózdz, 1995), support monophyly of the subfamily, relative to the Haemonchinae (Hoberg and Lichtenfels, 1994). In a limited manner, the phylogenetic tree for this restricted group of Ostertagia spp. and Teladorsagia can be used to examine hypotheses for character polarity and evolution, particularly for the synlophe, bursa and genital cone (e.g., Hoberg et al., 1993; Hoberg and Lichtenfels, 1994) and for host-association (e.g., Drózdz, 1967). As a result, we have mapped and optimized morphological characters onto 


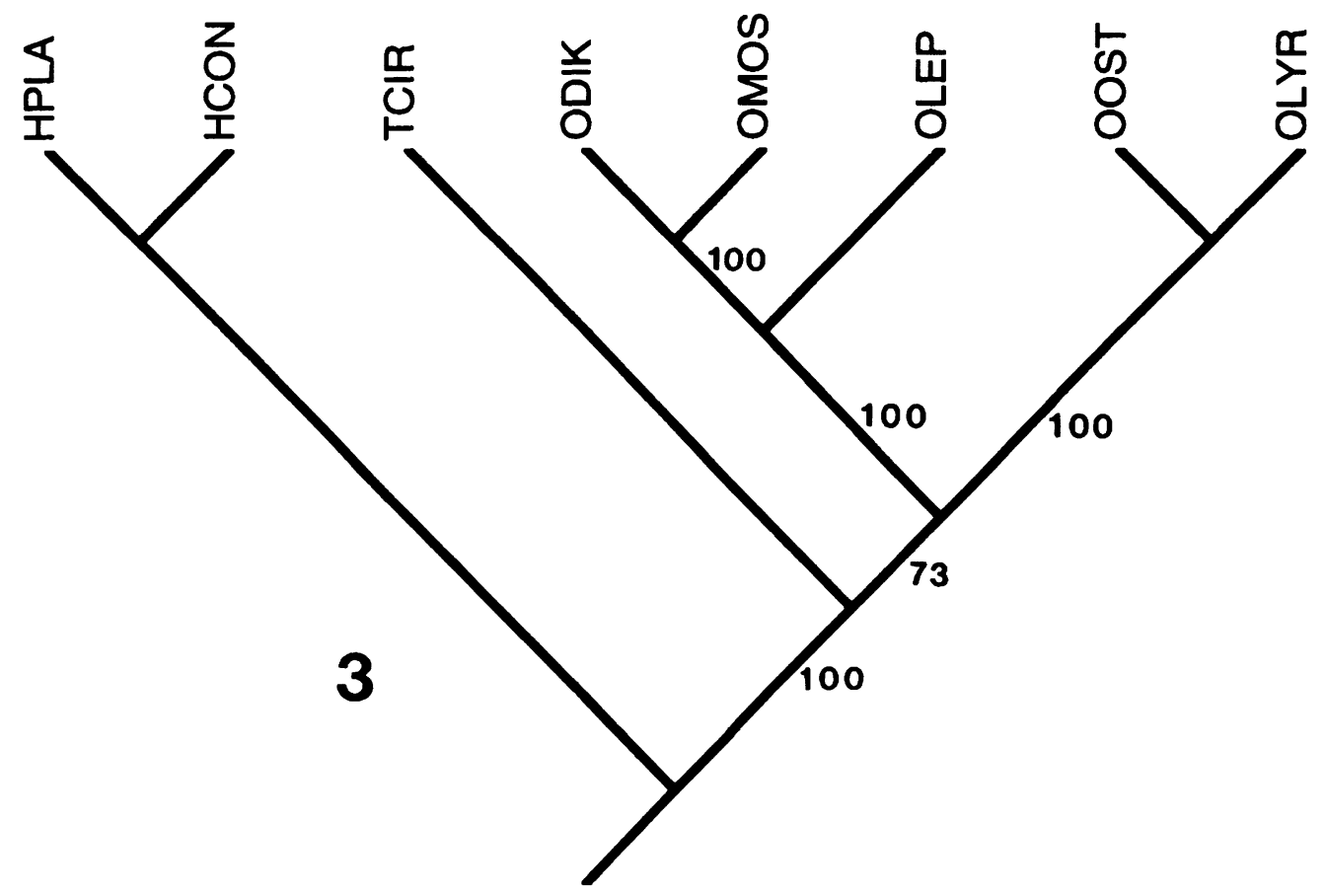

FIGURE 3. Phylogenetic hypothesis based on ITS-1 rDNA sequences for some ostertagiine nematodes. This single most parsimonious tree was derived from maximum parsimony $(\mathrm{CI}=0.92)$ and is congruent with bootstrap analysis. Bootstrap values are shown for each node. Taxa include Haemonchus contortus (HCON) and $\mathrm{H}$. placei (HPLA) in the outgroup and Teladorsagia circumcincta (TCIR), Ostertagia dikmansi (ODIK), O. mossi (OMOS), O. leptospicularis (OLEP), O. ostertagi (OOST), and O. lyrata (OLYR) in the in group.

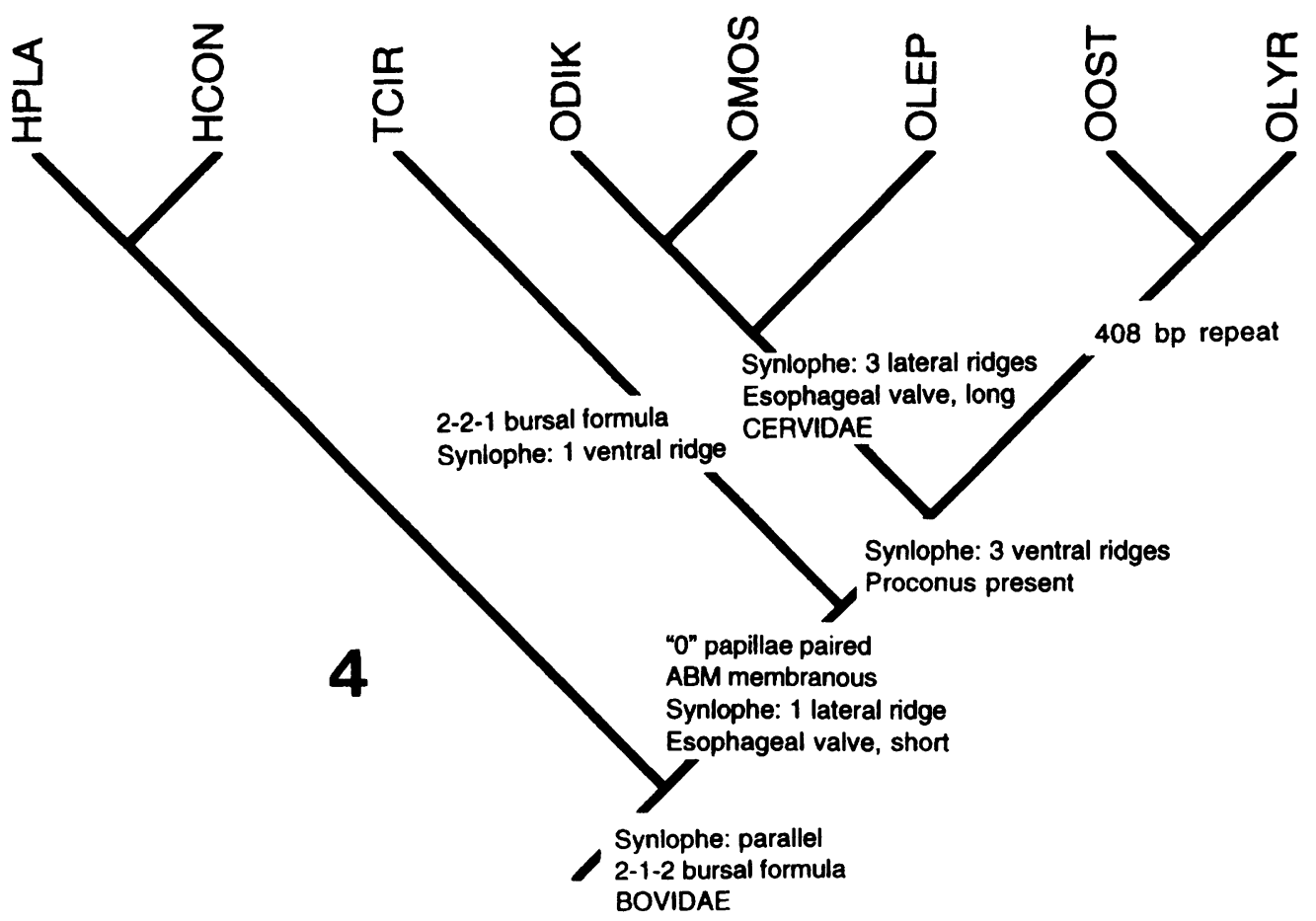

FIGURE 4. Morphological and genetic characters for Ostertagiinae mapped and optimized onto the tree derived from the ITS-1 rDNA sequence data analysis (Fig. 2). Taxa are labeled as in Figure 3. This hypothesis is consistent with the following as plesiomorphic in the subfamily: (1) parallel synlophe; (2) 2-1-2 bursa; and (3) bovid hosts as ancestral for ostertagiines. Other interpretations are outlined in the text. 
the phylogenetic hypothesis independently derived from ITS-1 sequence data. It is apparent that the 2-1-2 form of the ventral and lateral rays of the copulatory bursa and a parallel synlophe are plesiomorphic and the "ostertagiines" can be defined by a membranous accessory bursal membrane, and paired " $O$ " papillae relative to other trichostrongylids and the haemonchine sister group (see Hoberg and Lichtenfels, 1994).

The presence of a short esophageal valve, and a "Type I" lateral tapering synlophe with a single lateral ridge (see Lichtenfels et al., 1988a, 1988b), further define Teladorsagia $+O$ stertagia. At this level of analysis, Teladorsagia is distinguished from Ostertagia by the 2-2-1 form of the bursa and the presence of a single ventral ridge in the cervical zone (Lichtenfels et al., 1988b); however, the form of the bursa is not a synapomorphy for the genus (Hoberg et al., 1993; Hoberg and Lichtenfels, 1994; Lichtenfels et al., 1996). The species of Ostertagia analyzed in the present study share the presence of a proconus in the ventral aspect of the genital cone and 3 ventral ridges in the synlophe. The system of 3 lateral ridges, a "Type II" lateral synlophe, an elongate esophageal valve, and cervid hosts, on the other hand, are characteristic of $O$. mossi/O. dikmansi $+O$. leptospicularis, which are also grouped as sister species with respect to the DNA data. Additionally, the DNA and morphological data are consistent with the occurrence of Ostertagia among cervids resulting from a host-switch by an ancestral species from bovids.

We previously presented data (Zarlenga, Stringfellow, and Lichtenfels, 1994; Zarlenga, Stringfellow, Nobary, and Lichtenfels, 1994) indicating that the ssrDNA sequence will likely be uninformative for phylogenetic inference among this group of parasites because of the lack of sufficient diversity within the gene. It is equally possible that mtDNA sequence data will be uninformative in resolving phylogenetic issues within this genus given the high level of sequence polymorphism within this molecule. Though it may be argued that the mitochondrial-derived COX-1 sequence is inappropriate for this investigation, or that a larger mitochondrial-derived data set is necessary for a more thorough analysis, prior studies suggest that the level of polymorphism within this molecule is ubiquitous (Blouin et al., 1992) and that this polymorphism exists at the level of individual parasites. Thus, one might expect a similar level of unresolved sequence characters within other regions of this mtDNA as well. Nonetheless, the pairwise similarity scores presented herein strongly support and offer yet another level of resolution to the hypothesis for male dimorphism in the single species represented by $O$. ostertagi/O. lyrata and $O$. mossi/O. dikmansi. On the other hand, the application of additional genetic data to the phylogenetic analyses of the Ostertagiinae is necessary to more completely delineate issues such as character evolution, the basis for recognition and differentiation of generic-level taxa, and the history of host-parasite associations. It remains questionable whether mtDNA will provide the additional data source to resolve these issues.

\section{ACKNOWLEDGMENTS}

We are grateful to Louis Gasbarre, Patricia A. Pilitt, Arthur Abrams, and Lisa Davis for their assistance in collecting and identifying parasite specimens.

\section{LITERATURE CITED}

Blouin, M. S., J. B. Dame, C. A. Tarrant, and C. H. Courtney. 1992. Unusual population genetics of a parasitic nematode: mtDNA variation within and among populations. Evolution 46: 470-476.

- C. A. Yowell, C. H. Courtney, and J. B. Dame. 1995. Host movement and the genetic structure of populations of parasitic nematodes. Genetics 141: 1007-1017.

Dame J. B., K. D. Murrell, D. E. Worley, and G. A. Schad. 1987. Trichinella spiralis: Genetic evidence for synanthropic subspecies in sylvatic hosts. Experimental Parasitology 64: 195-203.

DASKALOV, P. 1974. On the reproductive relationships between Ostertagia circumcincta, Teladorsagia davtiani and $O$. trifurcata (Nematoda: Trichostrongylidae). Izv Tsentr. Khelmintol. Lab. 17: 59-72. [In Bulgarian] (Helminthological Abstracts 44: 949.)

DRózDZ, J. 1967. Studies on helminths and helminthiases in Cervidae III. Historical formation of helminthofauna in Cervidae. Acta Parasitologica Polonica 14: $287-300$.

. 1974. The question of genetic isolation and of permanent coincidence of some species of the subfamily Ostertagiinae. In Third Internal Congress of Parasitology Proceedings, Vol. 1, 25-31 August, Munich, Germany. FACTA Publications, Verlag H. Egermann, Vienna, Austria, p. 477-478.

- 1995. Polymorphism in the Ostertagiinae Lopez-Neyra, 1947 and comments on the systematics of these nematodes. Systematic Parasitology 32: 91-99.

DuRETTE-DESSET, M. C. 1982. Sur les divisions génériques des Nématodes Ostertagiinae. Annales de Parasitologie Humaine et Comparée 57: 375-381.

. 1989. Nomenclature proposée pour les espèces décrites dans la sous-famille des Ostertagiinae Lopez-Neyra, 1947. Annales de Parasitologie Humaine et Comparée 64: 356-373.

Garey, J. R., AND D. R. Wolstenholme. 1989. Platyhelminth mitochondrial DNA: Evidence for early evolutionary origin of a $t-$ RNA $^{\text {ser }} A G N$ that contains a dihydrouridine arm replacement loop, and a serine-specifying AGA and AGG codons. Journal of Molecular Evolution 28: 374-387.

Gasnier, N., J. CABARET, AND V. Suarez. 1993. Species and morphs in the Ostertagiinae: An allozyme study of seven species. International Journal for Parasitology 23: 765-770.

GibBOnS, L. M., AND L. F. KHalil. 1982. A key for identification of genera of the nematode family Trichostrongylidae Leiper, 1912. Journal of Helminthology 56: 185-233.

Higgins, D. G., AND P. M. ShaRp. 1988. Clustal: A package for performing multiple sequence alignment on a microcomputer. Gene 73: $237-244$.

Hoberg, E. P., AND J. R. Lichtenfels. 1994. Phylogenetic systematic analysis of the Trichostrongylidae (Nematoda), with an initial assessment of coevolution and biogeography. Journal of Parasitology 80: 976-996.

, AND P. A. PILITT. 1993. Affiliation of Hyostrongylus rubidus (Nematoda: Trichostrongylidae) with the Ostertagiinae, and evaluation of the synlophe and other structural characters. Journal of the Helminthological Society of Washington 60: 219-233.

Hoste, H., N. B. Chilton, R. A. Gasser, and I. Beveridge. 1995. Differences in the second internal transcribed spacer (ribosomal DNA) between five species of Trichostrongylus (Nematoda: Trichostrongyloidea). International Journal for Parasitology 25: 7580.

Humbert, J. F., AND J. CABARET. 1995. Use of random amplified polymorphic DNA for identification of ruminant trichostrongylid nematodes. Parasitology Research 81: 1-5.

JANSEN, J. 1989. A concise history of the Ostertagiinae Lopez-Neyra, 1947 (Nematoda: Trichostrongyloidea) and a discussion on its composition. Acta Leidensia 58: 151-159.

LANCASTER, M. B., AND C. HONG. 1981. Polymorphism in nematodes. Systematic Parasitology 3: 28-31.

Lichtenfels, J. R., AND E. P. HoberG. 1993. The systematics of nematodes that cause ostertagiasis in domestic and wild ruminants in North America; an update and a key to species. Veternary Parasitology 46: 33-53.

, P. A. PilitT, And T. M. Craig. 1996. The synlophe and other structural characteristics of Sarwaria bubalis (Nematoda: 
Trichostrongyloidea) from cattle in Guyana. Journal of Parasitology 82: 146-154.

, P. A. Pilitt, AND E. P. Hoberg. 1994. New morphological characters for identifying individual specimens of Haemonchus spp. (Nematoda: Trichostrongyloidea) and a key to species in ruminants of North America. Journal of Parasitology 80: 107-119.

, - - AND M. B. LANCASTER. 1988a. Cuticular ridge patterns of seven species of Ostertagiinae (Nematoda) parasitic in domestic ruminants. Proceedings of the Helminthological Society of Washington 55: 77-88.

1988b. Systematics of the nematodes that cause ostertagiasis in cattle, sheep and goats in North America Veterinary Parasitology 27: 3-12.

MOORE, W. S. 1995. Inferring phylogenies from mtDNA variation: Mitochondrial-gene trees versus nuclear-gene trees. Evolution 49: 718-726.

Stevenson, L. A., R. B. GASSER, AND N. B. Chilton. 1996. ITS2 rDNA of Teladorsagia circumcincta, T. trifurcata and T. davtiani (Nematoda: Trichostrongyloidea) indicates that these taxa are one species. International Journal of Parasitology 26: 1123-1126.

SuAREZ, V. H., AND J. CABARET. 1992. Interbreeding in the subfamily Ostertagiinae (Nematoda: Trichostrongyloidea) of ruminants. Journal of Parasitology 78: 402-405.
AND L. GRUNER 1995. Morphological polymorphism in the nematode Teladorsagia circumcincta in relation to age of larvae, infection mode and lamb characteristics in experimental conditions. International Journal of Parasitology 25: 1173-1177.

SwOFFORD, D. 1993. Phylogenetic analysis using parsimony. Version 3.1.1 computer distributed by Illinois Natural History Survey, Champaign, Illinois.

Tarrant, C. A., M. S. Blouin, C. A. Yowell, and J. B. Dame. 1992 Suitability of mitochondrial DNA for assaying interindividual genetic variation in small helminths. Journal of Parasitology 78: 374 378.

Wilbur, W. J. AND D. J. LiPMAN. 1983. Rapid similarity searches of nucleic acid and protein data banks. Proceedings of the National Academy of Sciences USA 80: 726-730.

ZarlengA, D. S., F. Stringfellow, AND J. R. Lichtenfels. 1994. Cloning and sequence analysis of the small subunit ribosomal RNA gene from Nematodirus battus. Journal of Parasitology 80: 342 344.

一, — M. Nobary, And J. R. Lichtenfels. 1994. Cloning and characterization of ribosomal RNA genes from three species of Haemonchus (Nematoda: Trichostrongyloidea) and identification of PCR primers for rapid differentiation. Journal of Parasitology 78: $28-36$. 